\title{
Blockade of Mineralocorticoid and Glucocorticoid Receptors Reverses Stress-Induced Motor Impairments
}

\author{
Nafisa M. Jadavji Rebecca D. Supina Gerlinde A. Metz \\ Canadian Centre for Behavioural Neuroscience, University of Lethbridge, Lethbridge, Alta., Canada
}

\section{Key Words}

Stress · Corticosterone - Agonist · Antagonist · Movement, skilled

\begin{abstract}
Aim: Stress and glucocorticoids can influence movement performance and pathologies of the motor system. The classic notion assumes that the glucocorticoid receptor (GR) mediates the majority of stress-induced behavioral changes. Nevertheless, recent findings have attributed a more prominent role to the mineralocorticoid receptor (MR) in modulating behavior. The purpose of this study was to dissociate the impact of MR versus GR activation in movement and stressassociated motor disruption. Methods: Groups of male and female rats were tested in skilled reaching and open field behavior and treated peri-orally with either agonists or antagonists for MR and GR, respectively. Results: Selective acute activation of MR (aldosterone) and GR (dexamethasone) decreased movement success with a magnitude similar to stress-induced impairment in male and female animals. By contrast, antagonist treatment to block MR (RU-28318) or GR (Mifepristone, RU-486) prevented motor impairments caused by acute restraint stress or corticosterone treatment. Moreover, both antagonists reversed chronic stress- and glucocorticoid-induced motor impairments to values comparable to baseline levels. Higher success rates in treated ani-
\end{abstract}

mals were accompanied by improved performance of skilled limb movements. In addition, combined treatment with MR and $G R$ antagonists had additive benefit on aim and advance towards the reaching target. Conclusion: These observations suggest that MR or GR equally influence motor system function with partially synergistic effects. Males and females show comparable responses to MR and GR activation or blockade. The need for balanced activation of MRs and GRs in motor control requires consideration in intervention strategies to improve performance in health and disease.

Copyright $\odot 2011$ S. Karger AG, Basel

\section{Introduction}

An increase in circulating glucocorticoid levels is one of the main features of the stress response [1-3]. The major glucocorticoids, such as cortisol in humans and corticosterone (CORT) in rodents, can readily cross the blood-brain barrier and dynamically regulate the activity of the hypothalamic-pituitary-adrenal (HPA) axis through negative feedback. Corticosteroids exert their central actions mainly by binding to two types of corticosteroid receptors in the brain, the high-affinity mineralocorticoid or type-1 receptor (MR) and the low-affinity glucocorticoid or type-2 receptor (GR) [2, 4]. Accordingly, low basal CORT levels occupy MR, whereas high

\section{KARGER \\ Fax +41613061234 \\ E-Mail karger@karger.ch}

www.karger.com
(C) 2011 S. Karger AG, Basel

0028-3835/11/0944-0278\$38.00/0

Accessible online at:

www.karger.com/nen
Gerlinde A. Metz, PhD

Canadian Centre for Behavioural Neuroscience, University of Lethbridge

4401 University Drive

Lethbridge, AB T1K 3M4 (Canada)

Tel. +1 403394 3992, E-Mail gerlinde.metz@uleth.ca 
CORT levels progressively saturate GR $[5,6]$. Thus, GR has been attributed the predominant receptor in mediating HPA axis feedback inhibition.

As shown for the hippocampus, the presence of MR and GR renders a region particularly sensitive to glucocorticoid effects and modulates behavioral performance, such as spatial learning [7-9]. Research in rats [10] and chickens [11] proposed a differential role of MR and GR in behavior. Increased GR activity enhances anxiety- and despair-like behavior, while decreased GR and at the same time increased MR activity diminish these behaviors [12-14].

Although in comparatively lower density than in limbic regions, MR and GR have also been detected in regions participating in motor control, including the motor cortex, basal ganglia, cerebellum, and spinal cord [15-19], suggesting that corticosteroids are important modulators of motor function. Indeed, systemic administration of CORT or stress disturbs skilled and non-skilled movement at both acute and long-term intervals $[19,20]$. Moreover, motor function seems to be equally impaired by treatment with either stress or CORT [20-23]. These observations also apply to studies of brain damage. In rat models of stroke and Parkinson's disease, both stress and CORT can impair motor recovery $[21,24]$ and exaggerate loss of movement [22], respectively. Notably, the motor system shows sexual dimorphism in response to stress [25]. Both MR and GR are liable candidates to account for at least some of these effects.

The present study investigates the effects of MR and GR blockade on motor performance. The purpose of this study was threefold: (1) to compare the influence of MR and GR activation on skilled and non-skilled movement performance; (2) to investigate the effects of MR and GR blockade during the response to acute and chronic restraint stress or elevated circulating CORT levels, and (3) to determine possible sex differences in the response to MR and GR activation or blockade. The hypotheses were that MR or GR activation would produce comparable motor impairments (Experiment 1), while MR or GR antagonist would block stress- or CORT-induced motor impairments in male and female animals (Experiment 2).

\section{Animals and Methods}

\section{Animals}

Subjects were 80 adult male and 82 adult female Long-Evans hooded rats, raised at the University of Lethbridge vivarium. Animals were 90 days old and weighed 250-300 g (females) and 400$600 \mathrm{~g}$ (males) at the beginning of the experiment. Animals were initially housed in pairs in shoebox cages under a 12:12-hour light/dark cycle with light starting at 07:30 h. The housing room was maintained at a room temperature of $20^{\circ} \mathrm{C}$ and $30 \%$ relative humidity.

Prior to the experiment, rats were food deprived to $95 \%$ of their initial body weight to encourage participation in the reaching task. To maintain body weight, supplementary food was given daily in their home cages $5 \mathrm{~h}$ after behavioral testing was completed. Animals were weighed daily prior to testing. Water was available ad libitum. All video recordings and data were analyzed by an observer blind to the experimental conditions. The animal experiment was performed according to the standards set by the Canadian Council of Animal Care.

\section{Experimental Design}

Testing and training of the animals was performed during the light phase of the cycle each day. Figure 1 illustrates the time course of manipulations and behavioral assessments. Two experiments were performed, each involving animals pre-trained in the skilled reaching task (fig. 1A). Baseline measurements began after 21 days of daily training and were recorded on 5 consecutive days. Video recordings of skilled reaching and open field exploration were taken the day before the onset of any treatment (baseline).

Experiment 1 investigated the effects of MR and GR activation on motor performance (fig. 1B). Animals were administered a selective MR agonist (aldosterone; 10 males, 10 females) or a GR agonist (dexamethasone; 10 males, 10 females). Animals were tested for 5 days prior to treatment (baseline). Animals were then administered aldosterone from day 1 to day 3 of testing. On days 1 and 2, video recordings of skilled reaching and open field, respectively, were taken. On day 3, blood samples were collected and no behavioral data were recorded. From days 4 to 10, animals were continuously tested in skilled reaching to record a new baseline for further testing. Animals were then administered dexamethasone from day 11 to 13 . On days 11 and 12 , video recordings of skilled reaching and open field, respectively, were taken. On day 13, blood samples were collected again, but no behavioral tests were performed.

Experiment 2 investigated the role of MR and GR in mediating stress- or CORT-induced motor disturbance by GR or MR receptor block (fig. 1C). Animals were pre-trained and baseline measurements in skilled reaching were recorded (base). Animals were then divided into 7 groups, each with an equal number of male and female rats and matched based on their baseline reaching success: restraint stress and MR antagonist RU-28318 ( $n=26)$; restraint stress and GR antagonist RU-486 $(\mathrm{n}=24)$; CORT and MR antagonist RU-28318 ( $\mathrm{n}=25)$; CORT and GR antagonist RU-486 $(\mathrm{n}=22)$; restraint stress and MR/GR antagonists combined $(\mathrm{n}=18)$; restraint stress-only controls $(\mathrm{n}=20)$, and CORT only controls $(\mathrm{n}=$ 8). All animals were exposed to 15 days of either daily restraint stress or oral CORT treatments. Animals were treated with drugs on day 1 and on days 13-15 of stress or CORT exposure, respectively. Day 1 of stress or drug treatment is referred to as 'acute treatment', days 13-15 are referred to as 'chronic treatment'. On day 13 , skilled reaching and day 14 open field tasks were video recorded, and on day 15 of treatment, blood samples were collected.

\section{Physiological Manipulations}

Restraint Stress

Chronic mild restraint was used as a model to induce psychological stress [26-28]. Animals were placed in a transparent Plexi- 


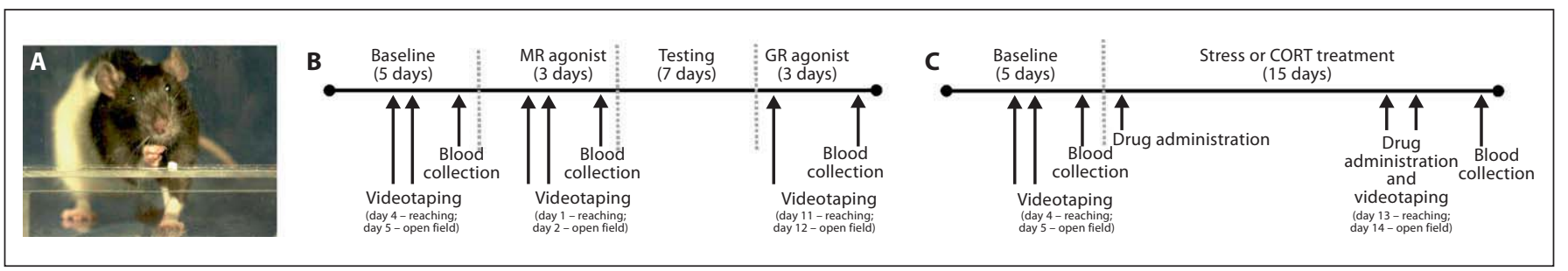

Fig. 1. Time chart illustrating the order of manipulations and behavioural tests. A Photograph of a rat reaching for pellets in the skilled reaching task. B Time course of Experiment 1 using single MR and GR agonist treatment. Skilled reaching and open field activity performance were assessed from video recordings prior to drug testing (baseline). The MR antagonist was administered on days 1-3. Video recordings of skilled reaching and open field were taken on days 1 and 2. Animals were tested in skilled reaching from days 1 to 12 . The GR agonist was administered from days 11 to 13 . Video recordings of skilled reaching and open field were taken on days 11 and 12. Blood samples for glucose concentrations were collected at baseline and on days 3 and 13 of testing. C Time course of Experiment 2 testing the influence of MR, GR or MR/ GR antagonists on performance during restraint stress or CORT treatment, respectively. Skilled reaching and open field activity performance were assessed from video recordings prior to (baseline) and at chronic time points. MR or GR antagonists were administered on days 1, 13 and 14 of restraint or CORT treatment. Blood samples were collected at baseline and chronic testing time points. No behavioral data were recorded on days when blood samples were collected. glas container ( $5 \mathrm{~cm}$ inner diameter) for a period of $20 \mathrm{~min} /$ day. The container had perforated ends to allow for ventilation. The container maintained the animals in a horizontal standing position without compression of the body. Behavioral testing or blood sampling took place $10 \mathrm{~min}$ after restraint.

\section{Systemic CORT Administration}

Oral CORT treatment was used to selectively induce elevated circulating glucocorticoid levels [20]. Animals received $10 \mathrm{mg} / \mathrm{kg}$ of oral CORT treatment (Sigma-Aldrich, Canada). Each dose of CORT was administered at the same time of day mixed with cookie crumbs, water and oil for consumption. Controls received cookie, water and oil only. Behavioral testing or blood sampling took place $60 \mathrm{~min}$ after CORT consumption [20].

\section{Systemic MR and GR Agonist and Antagonist Drug}

Administration

Drug treatment regimens were based on earlier data as indicated. Treatment intervals were chosen at which pharmacological action can be expected. Animals received oral treatment with the MR agonist, aldosterone (Sigma-Aldrich, Canada) given at $500 \mu \mathrm{g} /$ $\mathrm{kg} 1 \mathrm{~h}$ prior to testing [29]. The GR agonist, dexamethasone (Sigma-Aldrich, Canada) was given at $750 \mu \mathrm{g} / \mathrm{kg} 1 \mathrm{~h}$ prior to testing according to earlier data [30]. The MR antagonist, RU-28318 (Sigma-Aldrich, Canada) was given at $100 \mathrm{mg} / \mathrm{kg} 1 \mathrm{~h}$ prior to testing $[31,32]$. The GR antagonist, RU-486 (Mifepristone; Sigma-Aldrich, Canada) was given at $50 \mathrm{mg} / \mathrm{kg} 22 \mathrm{~h}$ prior to testing according to Baccan et al. [33]. The drugs were administered at the same time across days and mixed with cookie crumbs, water and oil for consumption. Controls received cookie crumbs, water and oil only.

\section{Behavioral Testing and Analysis}

Skilled Reaching Task

A reaching-for-food paradigm was used to assess skilled movement using detailed quantitative and qualitative scoring systems [34].
Skilled Reaching Task Apparatus. The reaching box was made of clear Plexiglas $(40 \times 45 \times 13.1 \mathrm{~cm})$. Animals were trained to extend a forelimb to reach for food pellets through a $1.3-\mathrm{cm}$-wide vertical opening in the middle of the front wall (fig. 1A). A shelf was positioned outside the front wall of the box $4 \mathrm{~cm}$ above the floor. Food pellets (45 mg banana-flavored Dustless Precision Pellets, Bioserv Inc., Frenchtown, N.J., USA) were placed in 1 of 2 small indentions on the shelf. The indentations were $2 \mathrm{~cm}$ away from the inside wall of the box and were centered on the edges of the slit through which the rats reached [34].

Training and Testing. Once rats began to reach for food, food pellets were placed individually in the indentation contralateral to the limb which the rat used for reaching. Between individual reaching movements, rats were required to leave the food aperture and walk to the rear of the box in order to reposition themselves prior to the next reach. Each training and testing session required each rat to reach for 20 food pellets. Reaching performance was scored by counting misses and successful reaches for each limb [34]. An 'attempt' was defined as a forelimb movement towards the pellet. The number of attempts for each session was recorded. A 'success' was recorded if an animal grasped a food pellet on the first attempt and withdrew the paw with the pellet through the slit to consume the food [34]. Percent reaching success was calculated by counting the number of successful reaches divided by the number of pellets (20) given in each session multiplied by 100 .

Video Taping and Analysis. On the last day of baseline and chronic drug treatment sessions, the animals' performance was video recorded from a frontal view for qualitative movement analysis. The rating of the reaching movements was performed from the videotapes using frame-by-frame inspection. The first 3 successful reaches were scored. Movements were analyzed using a framework derived from the Eshkol-Wachman movement notation which allows analysis of the relations and changes of relations between parts of the body and limbs [35]. In brief, the following 10 movement components of reaching were analyzed from a frontal view: orient; limb lift; digits close; aim; advance; digits open; 
pronation; grasp; supination I; supination II, and release [for details, see 34, 36]. For each of the 11 movement components, a score of 0 was given when the movement was absent, a score of 0.5 was given if the movement was present but abnormal, and a score of 1 was given if the movement was normal [34].

Open Field Task

The open field task was used as a measure of general locomotor and exploratory activity in stressed rats [28].

Apparatus. The open field box, measuring $100 \times 100 \times 18$ $\mathrm{cm}$, was made of opaque black Plexiglas. The bottom of the box was divided into 16 zones $(22 \times 22 \mathrm{~cm})$ using white masking tape.

Testing. Each rat was individually placed in the middle of the open field and video recorded for 5 min with a camera mounted above the open field [37]. After testing of each rat was completed, the floor of the box was cleaned with detergent.

Video Taping and Analysis. Video recordings were scored for horizontal activity (number of fields entered), vertical activity (number of rears), novel fields entered and percent time spent in the center and outside fields. Entered fields were scored when more than $50 \%$ of the animal's body crossed a subdivision of the open field.

\section{Video Recording Procedures}

Videotaping in all tasks was performed using a Sony ZR70 portable digital video camera. The shutter speed was set at 1/1,000 s. Tapes were analyzed frame-by-frame on a Sony Mini DV player. The testing setup was illuminated by a white light source (Lowel Inc., Hauppauge, N.Y., USA). In addition, the skilled reaching apparatus was also illuminated by a two-arm cold light source (Zeiss KL 1500, Carl Zeiss Inc., Jena, Germany).

Blood Glucose and Corticosterone Measurements

Blood samples were collected instead of behavioral testing between 09:00 and 10:30 h. Rats were anesthetized using 4\% isoflurane. Anesthesia lasted less than $5 \mathrm{~min}$ in which $1.0 \mathrm{ml}$ blood was collected from the tail vein. Syringes and needles used to collect blood were rinsed with the anticoagulant heparin. Blood glucose was measured using an Ascensia Breeze Blood Glucose Meter (Bayer, Toronto, Ont., Canada). The remaining blood was transferred to centrifuge tubes and plasma was obtained by centrifugation at $10,000 \mathrm{rpm}$ for $8 \mathrm{~min}$. The samples were stored at $-20^{\circ} \mathrm{C}$. Plasma CORT levels were determined by enzyme-linked immunosorbent assay (ELISA) [38]. ELISA analyses were performed using CORT EIA Kits (Cayman Chemical, Ann Arbor, Mich., USA). Limits of detection were between 24 and 10,000 pg/ml for ELISA analysis. CORT concentrations with a coefficient of variation of $<20 \%$ for the ELISA were used for statistical analysis.

\section{Statistical Analysis}

The statistical analysis was performed using a Statview software package 5 for Macintosh (Abacus Concepts, Inc., Berkeley, Calif., USA, 1995). The results were subject to analysis of variance (ANOVA) for repeated measurements with sex, group and test session as independent measures. Reaching success, number of reaching attempts, reaching movement scores, exploratory activity, rearing activity, blood glucose and CORT levels served as dependent variables. Post-hoc analysis included comparisons of means and variances between groups using Tukey's Honestly Significant Difference test for multiple comparisons and unpaired $t$ tests for differences between 2 groups. Within-group comparisons were assessed with

MR and GR Involved in Stress-Induced Motor Impairments independent and dependent sample t tests. In all statistical analyses, a $p$ value of $\leq 0.05$ was considered significant. All data are presented as mean \pm standard error of the mean (SEM).

\section{Results}

\section{Experiment 1: $M R$ and GR Activation}

\section{Skilled Reaching Success}

During baseline, animals achieved an average success rate of $47 \%$. There were no group differences at baseline. There also were no sex differences, so males and females were combined for further analyses. Success rates dropped significantly when administered a MR or GR agonist $\left(\mathrm{F}_{(1,17)}=31.08, \mathrm{p}<0.001\right.$; fig. $\left.2 \mathrm{~A}\right)$. The $\mathrm{MR}$ agonist significantly lowered reaching success on days land 2 when compared to training day 7 (all $t$ values $>3.29$, all $p$ values $<0.001$ ). Animals administered a GR agonist displayed significantly lower reaching success on days 11 and 12 when compared to training day 10 (all t values $>10.34$, all $\mathrm{p}$ values $>0.001$ ).

\section{Skilled Reaching Number of Attempts}

Due to absent sex differences, males and females were combined for further analyses. There was a significant difference in the number of attempts made between groups $\left(\mathrm{F}_{(1,17)}=27.2, \mathrm{p}<0.0001\right)$. As illustrated in figure 3, both MR and GR agonist treatments increased the number of attempts when compared to the last day of pretreatment baseline or testing (all $t$ values $<4.87$, all $\mathrm{p}$ values $<0.001)$. There was no difference in the time animals needed to complete 20 reaches, however. There was no difference between MR and GR agonist-treated animals.

\section{Skilled Reaching Movement Score}

There were no sex differences so that males and females were combined for further analyses. There was an overall difference between the baseline test session and administration of $\mathrm{MR}$ or GR agonist $\left(\mathrm{F}_{(2,50)}=7.75, \mathrm{p}<\right.$ $0.01)$. This difference was partially due to an inability to accurately aim and pronate the paw in agonist-treated animals, which may have contributed to overall impaired reaching success and the need to perform repeated attempts. Both MR and GR agonist-treated animals showed significant deficits in limb lift $\left(\mathrm{t}_{(17)}=6.86, \mathrm{p}<0.0001\right.$; $\mathrm{t}_{(15)}=7.29, \mathrm{p}<0.0001$, respectively), aim $\left(\mathrm{t}_{(17)}=4.97, \mathrm{p}<\right.$ $0.001 ; \mathrm{t}_{(15)}=3.55, \mathrm{p}<0.01$, respectively), pronation $\mathrm{t}_{(17)}=$ 5.55, $\mathrm{p}<0.001 ;\left(\mathrm{t}_{(15)}=-9.93, \mathrm{p}<0.01\right.$, respectively), and grasp $\left(\mathrm{t}_{(15)}=8.3, \mathrm{p}<0.001 ; \mathrm{t}_{(15)}=8.3, \mathrm{p}<0.0001\right.$, respectively). 


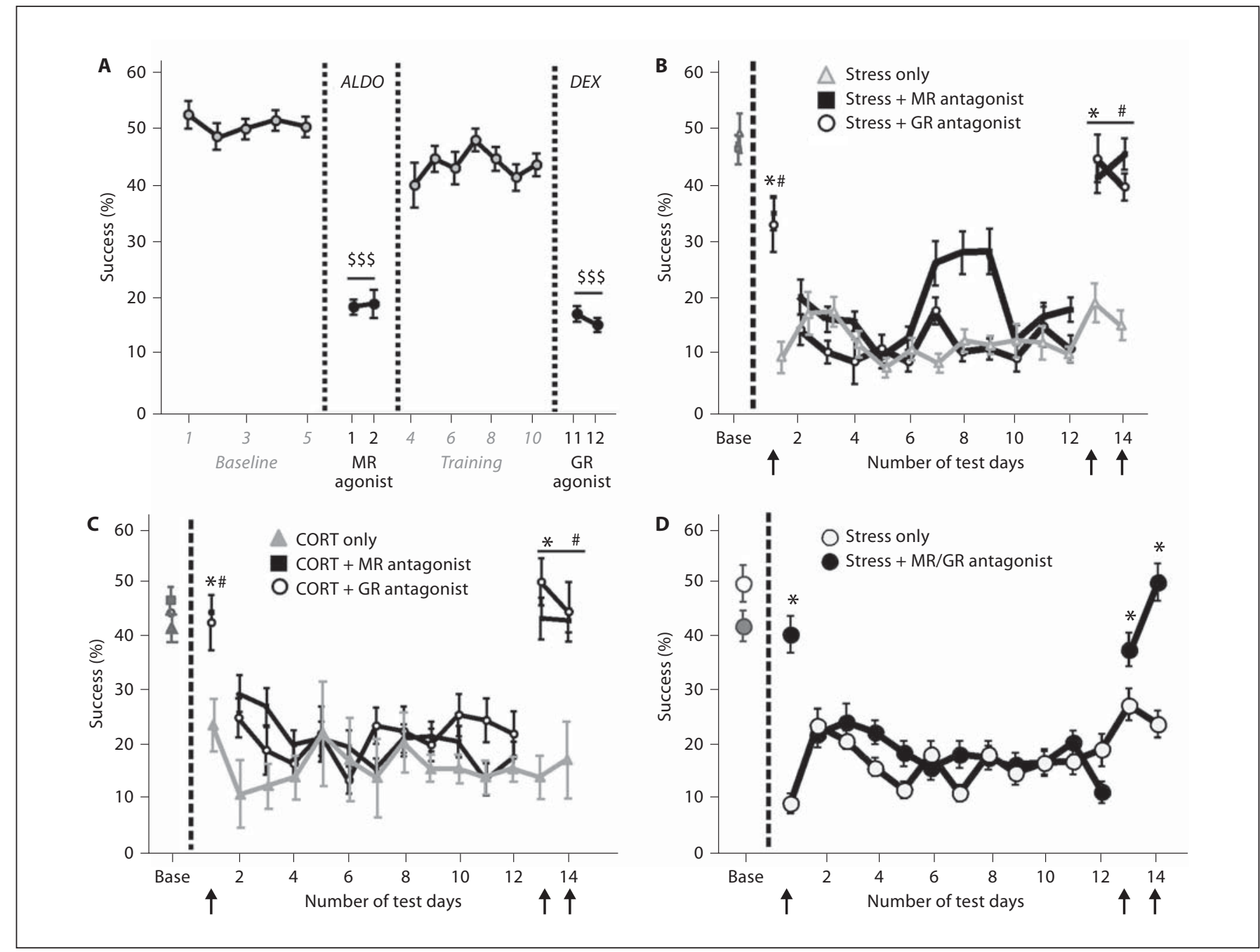

Fig. 2. Skilled reaching success. Percent success of animals treated with a MR or GR agonist (A), stress and either a MR or GR antagonist (B), CORT and either a MR or GR antagonist (C), or stress and MR and GR antagonist combined (D). Note the reduction in reaching success on days of MR agonist or GR agonist treatment when compared to the last day of training (A). Also note the preservation of reaching success in both MR- and GR-treated animals on days 1, 13 and 14 of daily stress or CORT. Data show male and

\section{Open Field Activity}

There was no difference between males and females, so groups were pooled together for further analyses. Both MR and GR agonist treatments altered overall exploratory activity when compared to baseline $\left(\mathrm{F}_{(2,52)}=15.11, \mathrm{p}<\right.$ $0.001)$. In particular, animals showed greater horizontal activity when administered the $\mathrm{MR}\left(\mathrm{t}_{(19)}=-4.18, \mathrm{p}<\right.$ $0.0001)$ or $\mathrm{GR}\left(\mathrm{t}_{(18)}=-5.40, \mathrm{p}<0.0001\right)$ agonists compared to baseline testing. Furthermore, animals administered

female animals combined. Symbols indicate significances: ${ }^{\$ \$} \mathrm{p}<$ 0.001 , paired t test comparison to previous baseline or no-drug test day, respectively; ${ }^{*} \mathrm{p}<0.05$, Tukey's honestly significant difference test comparison between GR antagonist (B, C) or combined MR/GR antagonist (D) with controls treated with CORT or stress only, respectively; ${ }^{\#} \mathrm{p}<0.05, \mathrm{MR}$ antagonist compared to stress-only controls. Arrows indicate drug treatment days.

the MR or GR agonist made more rears when compared to baseline $\left(\mathrm{t}_{(19)}=-5.19, \mathrm{p}<0.0001 ; \mathrm{t}_{(18)}=-5.23, \mathrm{p}<0.001\right.$, respectively).

\section{Blood Glucose Measurements}

There was no overall sex difference $\left(\mathrm{t}_{(78)}=-0.71, \mathrm{p}=\right.$ 0.48). MR agonist-treated animals showed significantly decreased blood glucose levels when compared to baseline measurements $\left(\mathrm{t}_{(48)}=3.21, \mathrm{p}<0.01\right)$. 

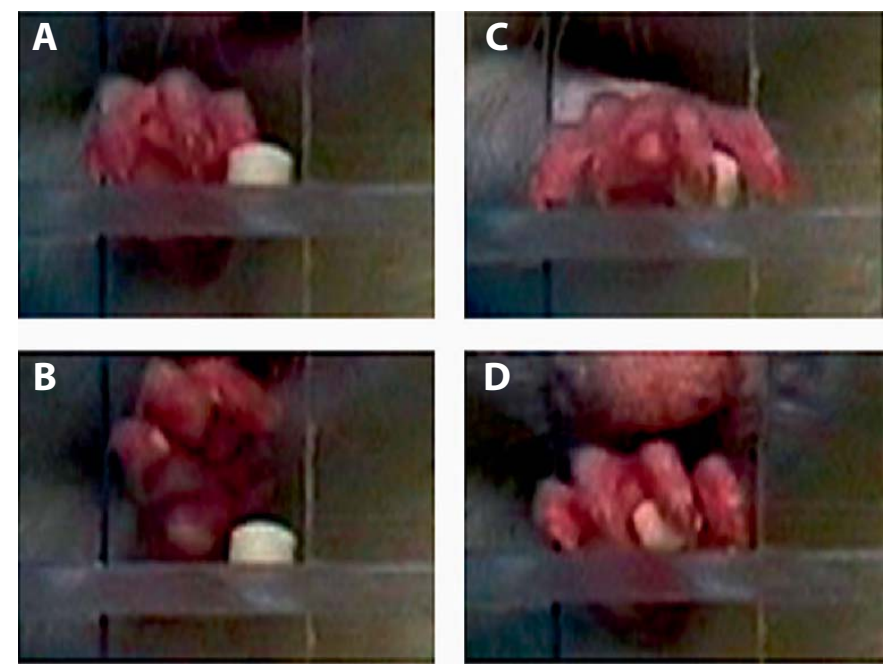

Fig. 3. Skilled reaching accuracy. Photographs illustrating a movement sequence of a reach scored as unsuccessful due to a second reaching attempt. The paw advances and is withdrawn (A) followed by a new advance to grasp the pellet (B-D). E The average number of reaching attempts for 20 pellets obtained in animals

\section{Plasma Corticosterone Measurements}

CORT concentrations in females treated with the MR agonist were lower than those in males $\left(\mathrm{F}_{(1,9)}=6.73\right.$, $\mathrm{p}<$ $0.05)$. There were no sex differences for treatment with the GR agonist, however. There was a significant main effect of group $\left(\mathrm{F}_{(1,4)}=3,417, \mathrm{p}<0.01\right)$ for GR agonist treatment. Administration of the GR agonist significantly lowered circulating CORT in all animals $\left(\mathrm{t}_{(5)}=5.16\right.$, $\mathrm{p}<0.01)$.

\section{Experiment 2: $M R$ and GR Block}

\section{Skilled Reaching Success}

Stress and Single Antagonist Treatment

During baseline, animals achieved an average success rate of $47 \%$. There was no sex difference between males and females at any time, so both groups were pooled for further analysis.

Figure $2 \mathrm{~B}$ shows that restraint stress significantly reduced reaching success by about $34 \%$ when compared to the last day of baseline ( $\mathrm{p}<0.05$, Tukey). There was a significant main effect of group $\left(\mathrm{F}_{(2,18)}=95.6, \mathrm{p}<0.0001\right)$. Furthermore, there was a significant interaction of group and test session $\left(\mathrm{F}_{(2,38)}=7.74, \mathrm{p}<0.0001\right)$. Reaching success improved, however, in animals administered either a MR or GR antagonist on days 1,13 , and 14 ( $\mathrm{p}<0.05$,

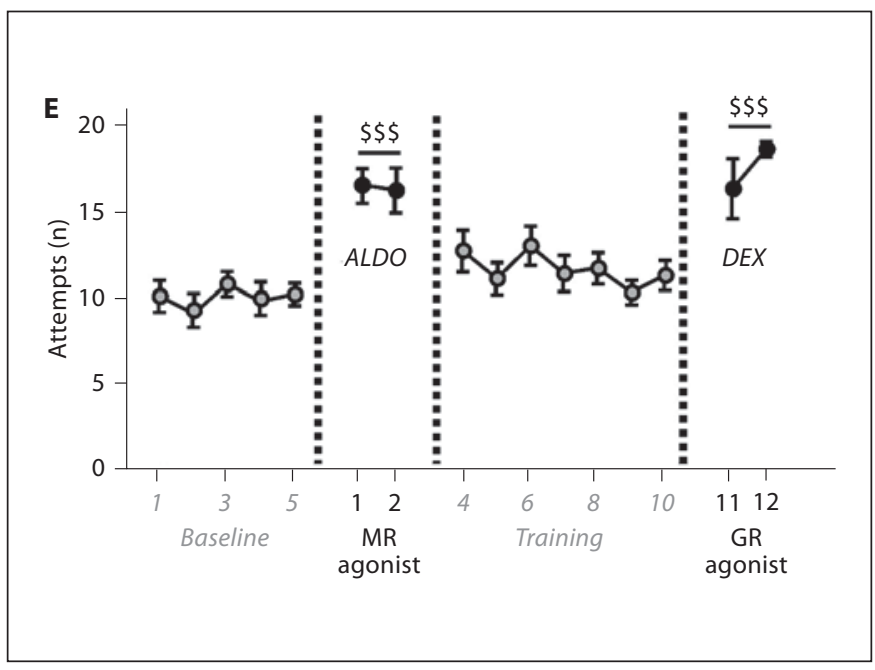

treated with a MR or GR agonist. Note the increase in reaching attempts on days of MR agonist or GR agonist treatment when compared to the last day of training. Symbols indicate significances: ${ }^{\$ \$} \mathrm{p}<0.001$, paired t test comparison to previous baseline or no-drug test day, respectively.

Tukey). Nevertheless, reaching success in drug-treated animals on days 1,13 and 14 was still lower than their baseline performance ( $\mathrm{p}<0.05$, Tukey).

\section{CORT and Single Antagonist Treatment}

There was no sex difference between males and females and so both groups were pooled together. Further analysis revealed a significant main effect of group $\left(\mathrm{F}_{(2,18)}=7.27, \mathrm{p}<0.01\right)$. There also was a significant interaction between group and test session $\left(\mathrm{F}_{(2,36)}=4.39, \mathrm{p}<\right.$ 0.001; fig. 2C). Specifically, GR antagonist-treated animals showed higher reaching success than CORT control and MR animals ( $p<0.05$, Tukey). Animals were significantly impaired in reaching success rates from days 2 to 12 of CORT treatments when compared to the last day baseline testing $\left(\mathrm{t}_{(24)}=2.13, \mathrm{p}<0.05\right.$; fig. $\left.2 \mathrm{C}\right)$. Notably, animals administered either antagonist had higher success rates on days 1,13 and 14 when compared to CORT only treatment $(\mathrm{p}<0.05$, Tukey).

\section{Stress and Combined Antagonist Treatment}

Stress-treated animals were exposed to a combined treatment of MR/GR antagonist (fig. 2D). There was a significant difference in reaching success between males and females $\left(\mathrm{F}_{(1,18)}=4.57, \mathrm{p}<0.05\right)$. Both females and males showed a significant interaction of group and test session $\left(\mathrm{F}_{(1,35)}=6.42, \mathrm{p}<0.0001 ; \mathrm{F}_{(1,18)}=5.33, \mathrm{p}<0.001\right.$, 
respectively) and a main effect of group $\left(\mathrm{F}_{(1,18)}=45.43\right.$, $\mathrm{p}<0.0001 ; \mathrm{F}_{(1,18)}=31.1, \mathrm{p}<0.0001$, respectively). Lastly, there was a significant main effect in males between drug-treated animals and stress-only controls $\left(\mathrm{F}_{(1,18)}=\right.$ 9.07, $\mathrm{p}<0.001$ ).

Overall, when treated with an acute dose of MR/GR antagonist, animals obtained more pellets when compared to day 2 in which only stress treatment was given $\left(\mathrm{t}_{(17)}=6.26, \mathrm{p}<0.001\right)$. Similarly, MR/GR antagonist treatment led to higher success rates when compared to stress controls on days 1,13 and $14\left(\mathrm{t}_{(36)}=8.05, \mathrm{p}<0.001\right.$; $\mathrm{t}_{(36)}=2.33, \mathrm{p}<0.05 ; \mathrm{t}_{(36)}=6.09, \mathrm{p}<0.001$; fig. $\left.2 \mathrm{D}\right)$.

\section{Skilled Reaching Number of Attempts}

Stress and Single Antagonist Treatment

There was a significant interaction between group and test session for both females and males $\left(\mathrm{F}_{(2,26)}=4.00, \mathrm{p}<\right.$ $0.0001 ; \mathrm{F}_{(2,26)}=4.74, \mathrm{p}<0.0001$, respectively). Males treated with MR antagonist differed from restraint stress controls ( $\mathrm{p}<0.05$, Tukey).

Overall, stress increased the number of attempts. By contrast, both the MR and GR antagonists prevented a stress-induced increase in the number of attempts on day 1 compared to baseline $\left(\mathrm{t}_{(22)}=-6.79, \mathrm{p}<0.001 ; \mathrm{t}_{(26)}=\right.$ $-3.14, \mathrm{p}<0.01$, respectively) or to stress-only controls $\left(\mathrm{t}_{(41)}=-8.55, \mathrm{p}<0.001 ; \mathrm{t}_{(45)}=5.75, \mathrm{p}<0.001 ;\right.$ data not shown).

CORT and Single Antagonist Treatment

There were no sex differences. There was a significant interaction between group and test session $\left(\mathrm{F}_{(2,26)}=1.64\right.$, $\mathrm{p}<0.05)$. Animals treated with the MR antagonist differed from GR animals ( $p<0.05$, Tukey) as well as the GR and CORT control animals ( $\mathrm{p}<0.05$, Tukey). On treatment days, the MR and GR antagonists reduced the number of reaching attempts when compared to CORT controls (all $\mathrm{t}$ values $<-4.13$, all $\mathrm{p}$ values $<0.001$; data not shown), indicating improved reaching accuracy.

Stress and Combined Antagonist Treatment

There were no sex differences so that males and females were pooled for further analyses. There was a significant main effect of group $\left(\mathrm{F}_{(1,18)}=613.00, \mathrm{p}<0.05\right)$. There was a significant interaction between group and test session $\left(\mathrm{F}_{(2,35)}=11.80, \mathrm{p}<0.0001\right)$. The MR/GR antagonist-treated animals made less attempts to obtain a food pellet than stress-only controls on days 1, 13 and 14 (all $\mathrm{t}$ values $<-14.39$, all $\mathrm{p}$ values $<0.001$; data not shown).

\section{Skilled Reaching Movement Score}

Stress and Single Antagonist Treatment

There were no sex differences so that males and females were pooled for further analyses. There was a main effect of group $\left(\mathrm{F}_{(2,42)}=7.47, \mathrm{p}<0.01\right)$. Specifically, $\mathrm{MR}$ and GR antagonist animals differed from stress-only controls ( $\mathrm{p}<0.05$, Tukey). Furthermore, there was also a significant difference between baseline and chronic stress time points $\left(\mathrm{F}_{(1,133)}=8.1, \mathrm{p}<0.01\right)$.

The movement components that were mainly affected by any of the treatments are illustrated in the panel of photographs in figure 4A. GR antagonist treatment increased the score for pronation above baseline $\left(\mathrm{t}_{(21)}=\right.$ $-3.51, \mathrm{p}<0.01)$ and control levels $\left(\mathrm{t}_{(40)}=2.63, \mathrm{p}<0.05\right.$; fig. 4B). Animals administered either MR or GR antagonist had higher grasp, supination I and supination II scores when compared to stress-only controls (all t values $>3.26$; all $\mathrm{p}$ values $<0.01$ or less; fig. $4 \mathrm{~B}$ ). These changes resulted in an increase in the total movement score for MR antagonist-treated animals above levels of stress-only controls $\left(\mathrm{t}_{(48)}=5.04, \mathrm{p}<0.001\right)$.

\section{CORT and Single Antagonist Treatment}

There were no sex differences. There was an overall effect of group $\left(\mathrm{F}_{(2,42)}=3.83, \mathrm{p}<0.001\right)$ because $\mathrm{MR}$ and GR animals differed from CORT-only controls $(\mathrm{p}<0.05$, Tukey). Treatment with either the MR or GR antagonist increased orient, digits close, digits open, and grasp movement scores when compared to CORT-only controls (all $t$ values $>2.05$, all $p$ values $<0.05$ or less; fig. $4 \mathrm{C}$ ). Animals administered the GR antagonist had higher pronation and supination II movement scores when compared to CORT controls (all $t$ values $>2.13$, all $\mathrm{p}$ values $<0.05)$.

\section{Stress and Combined Antagonist Treatment}

There were no sex differences, so males and females were pooled for further analysis. There was a significant difference between baseline and chronic stress testing time points $\left(\mathrm{F}_{(1,75)}=14.02, \mathrm{p}<0.001\right)$. Specifically, animals treated with the combined antagonist had a higher movement score during baseline when compared to the chronic stress time points $\left(\mathrm{t}_{(36)}=3.62, \mathrm{p}<0.001\right)$. Furthermore, animals treated with the combined antagonists performed significantly better than stress-only controls $\left(\mathrm{F}_{(1.75)}=40.59, \mathrm{p}<0.0001\right)$. As shown in figure $4 \mathrm{~B}$, antagonist-treated animals showed higher scores than stressonly controls in limb lift, aim, advance, grasp, supination I and supination II movement components (all t values $>2.04$, all $\mathrm{p}$ values $<0.05$ or higher). 


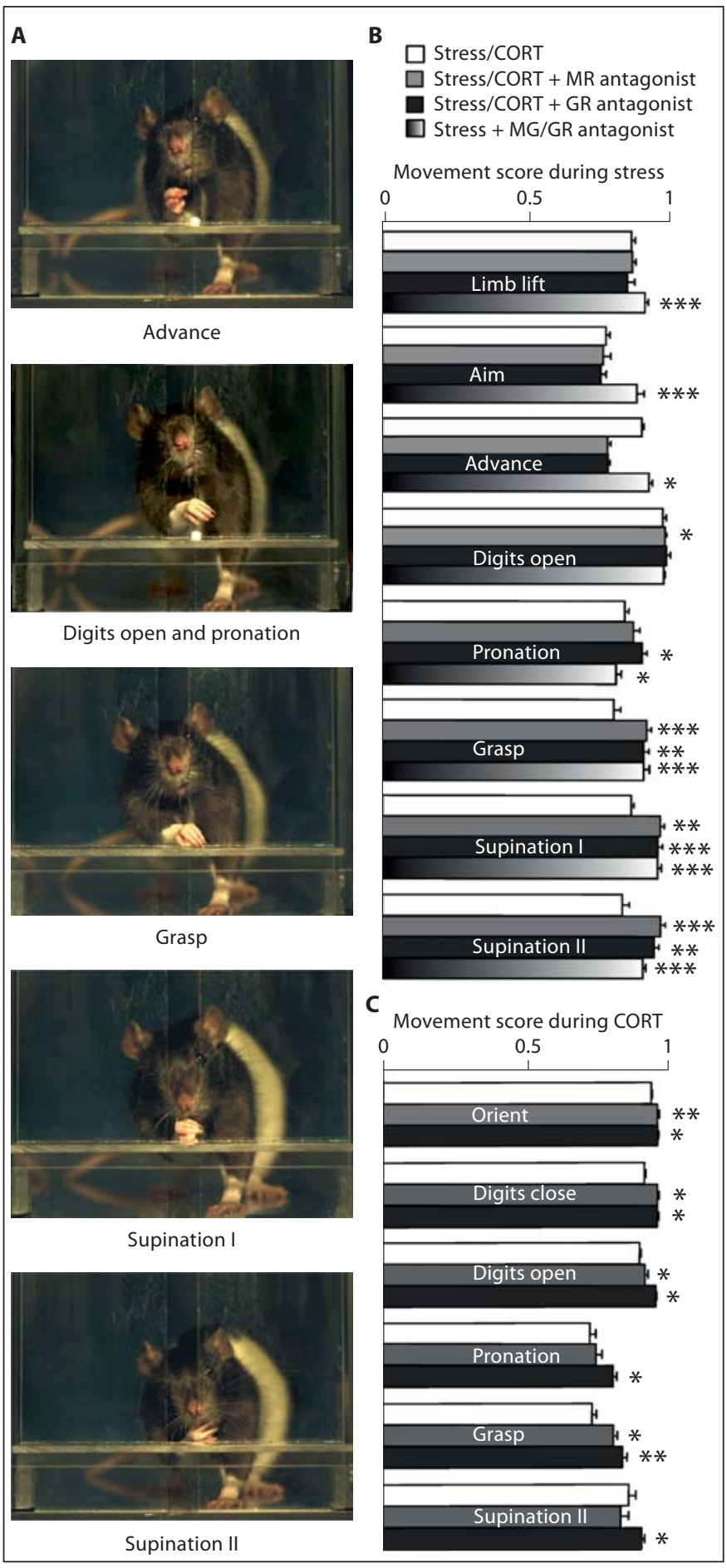

Fig. 4. Qualitative skilled reaching performance. A Sequential photographs of reaching movement components. The right panel shows movement scores for animals exposed to chronic restraint stress (B) and to CORT (C). Note that both MR or GR antagonists as well as combined treatment mainly enhanced movement scores. Asterisks indicate significances: ${ }^{*} \mathrm{p}<0.05 ;{ }^{* *} \mathrm{p}<0.001$, unpaired $\mathrm{t}$ test comparison between treated group and untreated control animals.

MR and GR Involved in Stress-Induced Motor Impairments

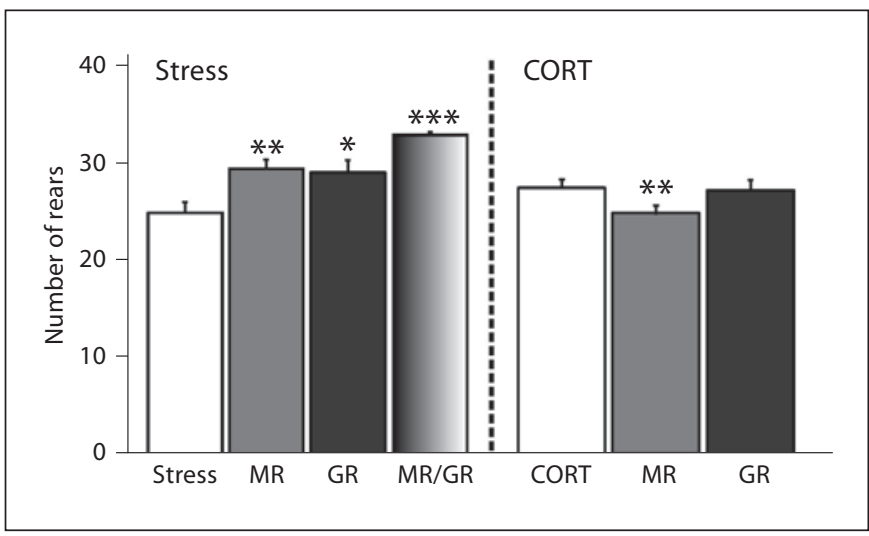

Fig. 5. Vertical activity in the open field. Note that MR, GR and combined MR/GR antagonist treatments reared more often than untreated controls in the stress condition (left), while the MR antagonist reduced rearing in the CORT condition (right). Combined treatment had additive effects in the stress condition. Asterisks indicate significances: ${ }^{*} \mathrm{p}<0.05 ;{ }^{* *} \mathrm{p}<0.01$; ${ }^{* *} \mathrm{p}<0.001$, unpaired $\mathrm{t}$ test comparison between antagonist treatment and untreated control animals.

\section{Open Field Activity}

Stress and Single Antagonist Treatment

There was an overall significant sex difference in animals administered the GR antagonist $\left(\mathrm{F}_{(1,21)}=11.54, \mathrm{p}<\right.$ 0.01 ). Males, but not females, showed an overall difference between MR, GR and stress-only control groups $\left(\mathrm{F}_{(2,68)}=18.97, \mathrm{p}<0.001\right)$. This difference in exploratory activity was mainly due to changes in vertical exploration. In particular, male animals administered the MR or GR antagonists made more rears than stress-only controls after chronic stress $\left(\mathrm{t}_{(44)}=3.16, \mathrm{p}<0.01 ; \mathrm{t}_{(41)}=2.29\right.$, $\mathrm{p}<0.05$, respectively; fig. 5). On the other hand, females reared more often after chronic stress when compared to baseline $\left(\mathrm{t}_{(11)}=-2.98, \mathrm{p}<0.05\right)$. Overall, animals administered the MR or GR antagonist reared more frequently than stress-only controls after chronic stress $\left(\mathrm{t}_{(44)}=3.16\right.$, $\mathrm{p}<0.01 ; \mathrm{t}_{(41)}=2.29, \mathrm{p}<0.05$, respectively; fig. 5).

\section{CORT and Single Antagonist Treatment}

There were no sex differences. Further analysis revealed a significant interaction between group, testing time point and open field activity $\left(\mathrm{F}_{(8,440)}=2.17, \mathrm{p}<0.05\right)$. While animals displayed lower levels of vertical exploration after chronic GR antagonist treatment $\left(\mathrm{t}_{(25)}=2.17\right.$, $\mathrm{p}<0.05$ ), animals treated with MR antagonist made more rears at the chronic CORT time point compared to baseline $\left(\mathrm{t}_{(24)}=-2.88, \mathrm{p}<0.05\right)$ or when compared to CORT controls $\left(\mathrm{t}_{(31)}=3.13, \mathrm{p}<0.01\right.$; fig. 5). 
Stress and Combined Antagonist Treatment

There was a significant sex difference between males and females $\left(\mathrm{F}_{(1,56)}=8.06, \mathrm{p}<0.01\right)$. Males showed an overall difference in overall open field activity between groups $\left(\mathrm{F}_{(1,34)}=8.48, \mathrm{p}<0.01\right)$. Males also showed a significant interaction between group and open field activity $\left(\mathrm{F}_{(4,136)}=2.79, \mathrm{p}<0.05\right)$. At the stress time point $\left(\mathrm{F}_{(1,36)}=3.72, \mathrm{p}<0.01\right)$, male MR/GR antagonist-treated animals spent significantly more time in outside fields $\left(\mathrm{t}_{(36)}=-2.10, \mathrm{p}<0.05\right)$, less time in the center fields $\left(\mathrm{t}_{(36)}=2.22, \mathrm{p}<0.05\right)$ and were more active $\left(\mathrm{t}_{(36)}=4.76\right.$, $\mathrm{p}<0.001$ ) than stress-only controls (fig. 5). Female animals showed an increase in activity from baseline to the chronic time point $\left(\mathrm{t}_{(9)}=-4.09, \mathrm{p}<0.01\right)$ and when compared to stress-only animals $\left(\mathrm{t}_{(9)}=-2.60, \mathrm{p}<0.05\right)$.

\section{Blood Glucose Measurements}

Stress and Single Antagonist Treatment

There were no sex differences. There was an overall group difference $\left(\mathrm{F}_{(2,123)}=3.21, \mathrm{p}<0.05\right)$. Specifically, the MR antagonist lowered blood glucose levels compared to stress-only controls ( $\mathrm{p}<0.05$, Tukey).

\section{CORT and Single Antagonist Treatment}

There were no sex differences. There was an overall effect of group $\left(\mathrm{F}_{(2,117)}=40.1, \mathrm{p}<0.0001\right)$. Specifically, animals administered either the MR or GR antagonist had lower blood glucose levels when compared to CORT only controls $(\mathrm{p}<0.05)$.

Stress and Combined Antagonist Treatment

There were no sex differences. Animals had lower blood glucose levels at the chronic time point when compared to baseline $\left(\mathrm{t}_{(76)}=-1.99, \mathrm{p}<0.05\right)$.

\section{Plasma Corticosterone Measurements}

Stress and Single Antagonist Treatment

A significant sex difference was observed in animals administered the GR antagonist $\left(\mathrm{F}_{(1,18)}=10.39, \mathrm{p}<0.01\right)$ due to higher levels in female animals. Animals treated with MR antagonist had a higher plasma CORT concentration at the chronic time point when compared to baseline $\left(\mathrm{t}_{(19)}=-2.93, \mathrm{p}<0.01\right)$.

\section{CORT and Single Antagonist Treatment}

There was a significant sex difference among animals administered either the $\mathrm{MR}$ and GR antagonists $\left(\mathrm{F}_{(1,14)}=\right.$ $10.05, \mathrm{p}<0.01 ; \mathrm{F}_{(1,10)}=24.61, \mathrm{p}<0.01$; respectively). Males had a higher plasma CORT level at the chronic time point when compared to baseline $\left(\mathrm{t}_{(8)}=-3.44, \mathrm{p}<0.01\right)$.
Stress and Combined Antagonist Treatment

There was an overall increase in CORT levels after chronic stress when compared to baseline $\left(t_{(13)}=-2.63\right.$, $\mathrm{p}<0.05)$.

\section{Discussion}

The present study provides evidence that both types of brain corticosteroid receptors are involved in modulating motor control. Single and repeated blockade of both MR and GR diminished skilled reaching accuracy as indicated by reduced skilled reaching success along with an increased number of attempts. In turn, MR and GR blockade ameliorated the effects of stress and elevated CORT levels by preserving success rates and reaching attempts. Moreover, while stress and elevated CORT reduced movement patterns of skilled reaching, antagonist treatment preserved limb trajectories. Combined antagonist treatment had cumulative effects on enhancement of locomotor activity and qualitative aspects of movement performance, but not success rates. Most notably, the results indicate that MR or GR cooperate to produce stress-induced motor impairments.

The stress- and CORT-induced motor deficits shown here confirm previous studies of diminished reaching success and movement scores [20, 22, 23]. Appropriate changes in plasma CORT and glucose also confirm the salience of the present manipulations. The present findings support the feasibility of skilled reaching tasks in rats as a sensitive model to investigate the mechanisms of corticosteroid actions in motor control. Furthermore, in line with earlier data motor performance in both males and females is significantly affected by acute and chronic stress [25]. According to the previous findings, fine motor control in male and female rats was equally susceptible to the disrupting effects of stress and CORT and responded to pharmacological intervention. It is therefore reasonable to expect that stress modulates motor control based on the presence of GR in regions participating in motor control.

Immunohistochemical studies have confirmed the presence of GR in the motor cortex, basal ganglia, and cerebellum [15-16], thus rendering these areas sensitive to glucocorticoid actions. By contrast, MR in the motor system appears to be restricted to cortical layers II, III and $\mathrm{V}$ [39]. Layer $\mathrm{V}$ is particularly relevant to the control of skilled reaching because its pyramidal cells give rise to the corticospinal tract, the main efferent projection of the motor cortex concerned with skilled movement in the rat 
$[40,41]$. In the present study, the positive responses to any of the drug treatments suggest that they were pharmacologically active at the time of behavioral testing. The novelty of the present study is to propose that both MR and GR may either directly or indirectly participate in fine and gross motor control.

The present study was performed under the assumption that systemic MR and GR agonist and antagonist treatments permeate the blood-brain barrier. A large number of studies using systemic aldosterone, RU-486 and RU-28318 suggest prominent central pharmacological and behavioral actions of these drugs [29, 32, 30, 42, 43]. Although brain MRs are predominantly occupied by glucocorticoids, MRs do respond to aldosterone at low concentrations [44]. The elevated HPA axis activation after MR antagonist treatment supports the view that MR plays a vital role in negative feedback regulation and constraining the HPA axis response after stressful events [45]. Lastly, while dexamethasone may be unable to pass the blood-brain barrier [46], it may exert behavioral effects as a secondary consequence to endogenous glucocorticoid suppression and HPA axis modulation or by altering MR-mediated agonistic effects.

The effectiveness of the pharmacological interventions was revealed by the ability of both MR and GR antagonists to in part prevent the effects of acute stress and CORT, and to reverse the influence of chronic stress and CORT. Notably, the effects of antagonism in CORT-treated animals were stronger than in stressed rats. CORT treatment simulated a single aspect of HPA axis activation that could be targeted by specific MR and GR receptor antagonism. By contrast, stress induced a complex physiological response involving a variety of hormonal changes, including adrenergic stimulation, that likely could not be abrogated by any specific antagonist. Activation of the brain adrenergic and noradrenergic system during stress may stimulate adrenergic receptors that are widely distributed in the central nervous system, including sensorimotor cortex, striatum, cerebellum, and spinal motor areas [47-49]. Adrenergic stimulation influences activity in sensorimotor cortex [50] and striatum $[51,52]$ and may determine motor output directly or through modulation of anxiety [53]. Thus, differences in the responsiveness to pharmacological treatment may be due to the nature of HPA axis activation.

The observations after simultaneous antagonist treatment suggest partially synergistic effects of MR and GR in motor control. There is growing evidence that the MR cooperates with GR in the stress response [32, 54-57]. While the role of GR in the stress response has been well characterized, the involvement of MRs has been mainly seen in appraising stress severity during onset of the stress response [4]. Nevertheless, an increasing body of evidence suggests cooperative actions of MR and GR in HPA axis regulation. In humans and animals, combined MR/GR antagonist treatment demonstrated physiological redundancy of the two receptor types in regulating negative HPA axis feedback $[54,57,58]$. Behaviorally, the effects of combined or separate MR and GR stimulation and blockade may be task dependent. Thus, the present data contradict previous findings indicating that simultaneous blockade of MR and GR enhances emotionality, but they support the observation that both MR and GR antagonists have anxiolytic effects [59].

While motor performance may be directly modulated by MR and GR effects, activation or blockade of these receptors may also affect the emotional state of an animal, thus interfering with execution of rewarded behavior, such as skilled reaching. It was reported that stress and glucocorticoids have mainly anxiogenic properties altering open field behavior and locomotor activity in rodents [60-64]. Furthermore, aldosterone has anxiogenic properties [43], while MR antagonists have anxiolytic actions [59]. The former mechanism may account for the capacity of aldosterone to compromise reaching accuracy, while the latter were able to facilitate skilled movement performance. Accordingly, the present findings show that single or combined MR or GR antagonist administration reverses these effects of stress by stimulating or disinhibiting vertical exploratory activity. Individual differences in vertical exploration in particular represent a reliable measure of anxiety, but also reactivity to stressors and novelty [65-67]. Furthermore, the magnitude of rearing activity is associated with a characteristic dopaminergic and cholinergic profile $[68,69]$. While anxiolytic pharmacological effects $[20,70]$ or motivational aspects may also improve fine motor control, the stability of reaching time measures and the observed changes in the number of attempts rather emphasize central motor effects of the drug treatments. Nevertheless, without further central and peripheral pharmacokinetic measures the present behavioral observations preclude an unambiguous causal interpretation of the findings.

The present findings may have been influenced by dose-, test interval- and context-dependent effects that are typical for corticosteroids. For example, corticotropin-releasing factor or CORT inhibits open field locomotion in a dose-dependent manner [71, 72]. A similar relationship was found in skilled reaching for the effect of benzodiazepine treatment to reduce CORT levels [20]. In 
addition, Korte et al. [59] have shown the importance of the time interval between initial MR and GR blockade and memory testing to determine behavioral outcome. Thus, an altered physiological state based on preceding experience may alter the processing of information and possibly interact with motor performance. The interaction of MR and GR may determine the effects of CORT on the organization of behavioral patterns [73] including the coordination of the discrete components comprising a skilled reaching movement. Furthermore, the strength of antagonists or manipulations of endogenous corticosteroid levels on memory processes is dependent upon training intensity $[74,75]$, which may also apply to the acquisition and adaptation of skilled movements.

The present findings concur with previous observations of cognitive performance. Administration of MR agonists was shown to enhance hippocampal plasticity, and to facilitate long-term potentiation and other electrophysiological correlates of memory formation [76-78]. By contrast, an MR antagonist can block the response to CORT in a water maze [79]. In turn, an MR antagonist or combined MR/GR blockade without HPA axis activation may impair reference memory [7] or fear memory formation [80], emphasizing the importance that balanced activation of both MR and GR receptors is necessary for optimal behavioral function.
The present observations have clinical relevance in the context of movement disorders. For example, conditions such as Parkinson's disease and stroke may become exaggerated by the experience of stress [21, 22, 24, 81]. Blockade of MR and GR may represent a potential therapeutic target to facilitate symptomatic relief.

In conclusion, the present data indicate that both the MR and GR play a role in modulating the response to stress in terms of motor performance. The optimal performance of fine and gross movements likely requires a balanced activation of both MR and GR. The cooperation of MR and GR needs to be considered as a therapeutic target when developing new interventions for motor disorders.

\section{Acknowledgements}

The authors are grateful to Dora Capatos and Keri Colwell for assistance with the experiments. This research was supported by Alberta Innovates - Health Solutions (R.D.S., G.A.M.), the National Sciences and Engineering Research Council of Canada (G.A.M.) and the Canadian Institutes of Health Research (G.A.M.).

\section{References}

1 Selye H: Stress and distress. Compr Ther 1975;1:9-13.

2 de Kloet ER, Oitzl MS, Joels M: Stress and cognition: are corticosteroids good or bad guys? Trends Neurosci 1999;22:422-426.

$\checkmark 3$ Metz GA: Stress as a modulator of motor system function and pathology. Rev Neurosci 2007; 18:1-14.

4 de Kloet ER, Joels M, Holsboer F: Stress and the brain: from adaptation to disease. Nat Rev Neurosci 2005;6:463-475.

5 Reul JM, de Kloet, ER: Two receptor systems for corticosterone in rat brain: microdistribution and differential occupation. Endocrinology 1985; 17:2505-2511.

-6 de Kloet ER, Vreugdenhil E, Oitzl MS, Joëls M: Brain corticosteroid receptor balance in health and disease. Endocr Rev 1998;19:269_ 301.

-7 Douma BR, Korte SM, Buwalda B, la Fleur SE, Bohus B, Luiten PG: Repeated blockade of mineralocorticoid receptors, but not of glucocorticoid receptors impairs food rewarded spatial learning. Psychoneuroendocrinology 1998;23:33-44. $\checkmark 8$ Oitzl MS, Fluttert M, Sutanto W, de Kloet ER: Continuous blockade of brain glucocorticoid receptors facilitates spatial learning and memory in rats. Eur J Neurosci 1998; 10: 3759-3766.

-9 Yau JL, Noble J, Seckl JR: Continuous blockade of brain mineralocorticoid receptors impairs spatial learning in rats. Neurosci Lett 1999:277:45-48

10 Oitzl MS, de Kloet ER: Selective corticosteroid antagonists modulate specific aspects of spatial orientation learning. Behav Neurosci 1992;106:62-71.

-11 Sandi C, Rose SP: Corticosteroid receptor antagonists are amnestic for passive avoidance learning in day-old chicks. Eur J Neurosci 1994;6:1292-1297.

-12 Herrero AI, Sandi C, Venero C: Individual differences in anxiety trait are related to spatial learning abilities and hippocampal expression of mineralocorticoid receptors. Neurobiol Learn Mem 2006;86:150-159.

13 Jakovcevski M, Schachner M, Morellini F: Individual variability in the stress response of C57BL/6J male mice correlates with trait anxiety. Genes Brain Behav 2008;7:235-243.
14 Mitra R, Ferguson D, Sapolsky RM: Mineralocorticoid receptor overexpression in basolateral amygdala reduces corticosterone secretion and anxiety. Biol Psychiatry 2009; 66:686-690

15 Ahima RS, Harlan RE: Charting of type II glucocorticoid receptor-like immunoreactivity in the rat central nervous system. Neuroscience 1990;39:579-604.

16 Ahima RS, Tagoe CNB, Harlan RE: Type II corticosteroid receptor-like immunoreactivity in the rat cerebellar cortex: differential regulation by corticosterone. Neuroendocrinology 1991;55:683-694.

17 Marlier LN, Csikos T, Rebaudengo N, Borboni P, Patacchioli FR, Angelucci L, Privat A, Lauro R: Distribution of glucocorticoid receptor mRNA in the rat spinal cord. Neuroreport 1995;6:2245-2249.

18 Roland BL, Krozowksi ZS, Funder JW: Glucocorticoid receptor, mineralocorticoid receptors, 11 beta-hydroxysteroid dehydrogenase- 1 and -2 expression in rat brain and kidney: in situ studies. Mol Cell Endocrinol 1995;111:R1-R7. 
19 Metz GAS, Schwab ME, Welzl H: The effects of acute and chronic stress on motor and sensory performance in male Lewis rats. Physiol Behav 2001;72:29-35.

20 Metz GA, Jadavji NM, Smith LK: Modulation of motor function by stress: a novel concept of the effects of stress and corticosterone on behavior. Eur J Neurosci 2005;22: 1190-1200.

-21 Kirkland SW, Coma AK, Colwell KL, Metz GA: Delayed recovery and exaggerated infarct size by post-lesion stress in a rat model of focal cerebral stroke. Brain Res 2008;1201: 151-160.

22 Smith LK, Jadavji NM, Colwell KL, Perehudoff KS, Metz GA: Stress accelerates neural degeneration and exaggerates motor symptoms in a rat model of Parkinson's disease. Eur J Neurosci 2008;27:2133-2146.

-23 Zucchi FCR, Kirkland SW, Jadavji NM, van Waes LT, Klein A, Supina RD, Metz GA: Predictable stress versus unpredictable stress: a comparison in a rodent model of stroke. Behav Brain Res 2009;205:67-75.

24 Merrett DL, Kirkland SW, Metz GA: Synergistic effects of age and stress in a rodent model of stroke. Behav Brain Res 2010;214: 55-59.

25 Jadavji NM, Metz GA: Sex differences in skilled movement in response to restraint stress and recovery from stress. Behav Brain Res 2008;195:251-259.

-26 Garcia A, Marti O, Valles A, Dal-Zotto S, Armario A: Recovery of the hypothalamic-pituitary-adrenal response to stress. Effect of stress intensity, stress duration and previous stress exposure. Neuroendocrinology 2000; 72:114-125.

$\checkmark 27$ Faraday MM: Rat sex and strain differences in responses to stress. Physiol Behav 2002;75: 507-522.

-28 Mercier S, Canini F, Buguet A, Cespuglio R, Martin S, Bourdon L: Behavioural changes after an acute stress: stressor and test types influences. Behav Brain Res 2003;139:167175.

29 Devenport L, Thomas T, Knehans A, Sundstrom A: Acute, chronic, and interactive effects of type I and II corticosteroid receptor stimulation on feeding and weight gain. Physiol Behav 1990;47:1221-1228.

- 30 Ginsberg AB, Frank MG, Francis AB, Rubin BA, O'Connor KA, Spencer RL: Specific and time-dependent effects of glucocorticoid receptor agonist RU28362 on stress-induced pro-opiomelanocortin hnRNA, c-fos mRNA and zif268 mRNA in the pituitary. J Neuroendocrinol 2006;18:129-138.

- 31 Cole M, Kalman B, Pace T, Topczewski F, Lowrey M, Spencer R: Selective blockade of the MR impairs hypothalamic-pituitary-adrenal axis expression of habituation. J Neuroendocrinol 2000;12:1034-1042.
32 Pace T, Spencer R: Disruption of mineralcorticoid receptor function increases corticosterone responding to mild, but not moderate psychological stressor. J Physiol Endocrinol Metab 2005;288:E1082-1088.

33 Baccan GC, Oliveira RD, Mantovani B: Stress and immunological phagocytosis: possible nongenomic action of corticosterone. Life Sci 2004;75:1357-1368.

34 Metz GA, Whishaw IQ: Skilled reaching an action pattern: stability in rat (Rattus norvegicus) grasping movements as a function of changing food pellet size. Behav Brain Res 2000;116:111-122.

35 Eshkol N, Wachman A: Movement Notation. London, Weidenfeld and Nicolson, 1958.

36 Whishaw IQ, Pellis SM: The structure of skilled forelimb reaching in the rat: a proximally driven movement with a single distal rotatory component. Behav Brain Res 1990; 41:49-59.

37 Suchecki D, Duarte Palma B, Tufik S: Pituitary-adrenal axis and behavioural responses of maternally deprived juvenile rats to the open field. Behav Brain Res 2000;111:99106.

38 Kavushansky A, Richter-Levin G: Effects of stress and corticosterone on activity and plasticity in the amygdala. J Neurosci Res 2006;84:1580-1587.

39 Roland BL, Krozowksi ZS, Funder JW: Glucocorticoid receptor, mineralocorticoid receptors, 11 beta-hydroxysteroid dehydrogenase- 1 and -2 expression in rat brain and kidney: in situ studies. Mol Cell Endocrinol 1995;111:R1-R7.

40 Whishaw IQ, Metz GA: Absence of impairments or recovery mediated by the uncrossed pyramidal tract in the rat versus enduring deficits produced by the crossed pyramidal tract. Behav Brain Res 2002;134:323-336.

41 Whishaw IQ, Pellis SM, Gorny B, Kolb B, Tetzlaff W: Proximal and distal impairments in rat forelimb use in reaching follow unilateral pyramidal tract lesions. Behav Brain Res 1993;56:59-76.

42 Dalm S, Brinks V, van der Mark MH, de Kloet ER, Oitzl MS: Non-invasive stressfree application of glucocorticoid ligands in mice. J Neurosci Methods 2008;170:77-84.

43 Hlavacova N, Jezova D: Chronic treatment with the mineralocorticoid hormone aldosterone results in increased anxiety-like behavior. Horm Behav 2008;54:90-97.

44 de Kloet ER, Sutanto W, van den Berg DT, Carey MP, van Haarst AD, Hornsby CD, Meijer OC, Rots NY, Oitzl MS: Brain mineralocorticoid receptor diversity: functional implications. J Steroid Biochem Mol Biol 1993;47:183-190.

45 Bachman C, Lintorst A, Hosboer F, Reul J: Effect of chronic administration of selective of GR antagonist on the rat HPA axis. Neuropsychopharmacology 2003;28:1056-1067.

46 de Kloet ER: Why dexamethasone poorly penetrates in brain. Stress 1997;2:13-20.
47 Zilles K, Qü M, Schleicher A: Regional distribution and heterogeneity of alpha-adrenoceptors in the rat and human central nervous system. J Hirnforsch 1993;34:123-132.

-48 Summers RJ, Papaioannou M, Harris S, Evans BA: Expression of beta 3-adrenoceptor mRNA in rat brain. Br J Pharmacol 1995;116: 2547-2548.

-49 Day HE, Campeau S, Watson SJ Jr, Akil H: Distribution of alpha 1a-, alpha 1b- and alpha 1d-adrenergic receptor mRNA in the rat brain and spinal cord. J Chem Neuroanat 1997;13:115-139.

50 Bennett BD, Huguenard JR, Prince DA: Adrenergic modulation of GABAA receptormediated inhibition in rat sensorimotor cortex. J Neurophysiol 1998;79:937-946.

51 Berretta N, Bernardi G, Mercuri NB: Alpha(1)-adrenoceptor-mediated excitation of substantia nigra pars reticulata neurons. Neuroscience 2000;98:599-604.

52 Buck K, Ferger B: The selective alphal adrenoceptor antagonist HEAT reduces L-DOPA-induced dyskinesia in a rat model of Parkinson's disease. Synapse 2010;64:117-126.

53 Overstreet DH, Stemmelin J, Griebel G: Confirmation of antidepressant potential of the selective beta3 adrenoceptor agonist amibegron in an animal model of depression. Pharmacol Biochem Behav 2008;89: 623-626.

54 Smythe J, Murphy D, Timothy C, Costall B: Hippocampal mineralocorticoid, but not glucocorticoid receptors modulate anxiety like behavior in rats. Pharmacol Biochem Behav 1997;56:507-513.

55 Spencer R, Kim P, Klaman B, Cole M: Evidence for mineralocorticoid receptor facilitation of glucocorticoid receptor-dependent regulation of hypothalamic-pituitary-adrenal axis activity. Endocrinology 1998;139: 2718-2726.

56 Derijk RH, Wüst S, Meijer OC, Zennaro MC, Federenko IS, Hellhammer DH, Giachetti G, Vreugdenhil E, Zitman FG, de Kloet ER: A common polymorphism in the mineralocorticoid receptor modulates stress responsiveness. J Clin Endocrinol Metab 2006;91: 5083-5089.

57 Mattsson C, Reynolds RM, Simonyte K, Olsson T, Walker BR: Combined receptor antagonist stimulation of the hypothalamic-pituitary-adrenal axis test identifies impaired negative feedback sensitivity to cortisol in obese men. J Clin Endocrinol Metab 2009; 94:1347-1352.

58 Bradbury MJ, Akana SF, Dallman MF: Roles of type I and II corticosteroid receptors in regulation of basal activity in the hypothalamo-pituitary-adrenal axis during the diurnal trough and the peak: evidence for a nonadditive effect of combined receptor occupation. Endocrinology 1994;134:1286-1296. 
-59 Korte SM, de Boer SF, de Kloet ER, Bohus B: Anxiolytic-like effects of selective mineralocorticoid and glucocorticoid antagonists on fear-enhanced behavior in the elevated plusmaze. Psychoneuroendocrinology 1995;20: 385-394.

-60 Dunn AJ, File SE: Corticotropin-releasing factor has an anxiogenic action in the social interaction test. Horm Behav 1987;21:193-202.

61 Conrad CD, LeDoux JE, Magariños AM, McEwen BS: Repeated restraint stress facilitates fear conditioning independently of causing hippocampal CA3 dendritic atrophy. Behav Neurosci 1999;113:902-913.

-62 Sandi C, Merino JJ, Cordero MI, Touyarot K, Venero C: Effects of chronic stress on contextual fear conditioning and the hippocampal expression of the neural cell adhesion molecule, its polysialylation, and L1. Neuroscience 2001;102:329-339.

63 Woodson JC, Macintosh D, Fleshner M, Diamond DM: Emotion-induced amnesia in rats: working memory-specific impairment, corticosterone-memory correlation, and fear versus arousal effects on memory. Learn Mem 2003;10:326-336.

64 Ardayfio P, Kim KS: Anxiogenic-like effect of chronic corticosterone in the light-dark emergence task in mice. Behav Neurosci 2006;120:249-256.

-65 Gironi Carnevale UA, Vitullo E, Sadile AG: Post-trial NMDA receptor allosteric blockade differentially influences habituation of behavioral responses to novelty in the rat. Behav Brain Res 1990;39:187-195.
66 von Horsten S, Exton MS, Voge J, Schult M, Nagel E, Schmidt RE, Westermann J, Schedlowski M: Cyclosporine A affects open field behavior in DA rats. Pharmacol Biochem Behav 1998;60:71-76.

67 Pawlak CR, Schwarting RK: Object preference and nicotine consumption in rats with high vs. low rearing activity in a novel open field. Pharmacol Biochem Behav 2002;73: 679-687.

68 Thiel CM, Huston JP, Schwarting RK: Hippocampal acetylcholine and habituation learning. Neuroscience 1998;85:1253-1262.

69 Thiel CM, Schwarting RK: Dopaminergic lateralisation in the forebrain: relations to behavioural asymmetries and anxiety in male Wistar rats. Neuropsychobiology 2001; 43:192-199.

70 Metz GA, Gonzalez CLR, Piecharka DM, Whishaw IQ: Acute alcohol administration improves skilled reaching success in intact but not 6-OHDA dopamine depleted rats: a subsystems analysis of the motoric and anxiolytic effects of alcohol. Behav Brain Res 2003;142:167-174.

71 van den Buuse M, van Acker SA, Fluttert MF, de Kloet ER: Involvement of corticosterone in cardiovascular responses to an open-field novelty stressor in freely moving rats. Physiol Behav 2002;75:207-215.

72 Campbell BM, Morrison JL, Walker EL, Merchant KM: Differential regulation of behavioral, genomic, and neuroendocrine responses by CRF infusions in rats. Pharmacol Biochem Behav 2004;77:447-455.

73 Kolber BJ, Wieczorek L, Muglia LJ: Hypothalamic-pituitary-adrenal axis dysregulation and behavioral analysis of mouse mutants with altered glucocorticoid or mineralocorticoid receptor function. Stress 2008;11:321338.
4 Sandi C, Loscertales M, Guaza C: Experience-dependent facilitating effect of corticosterone on spatial memory formation in the water maze. Eur J Neurosci 1997;9:637642 .

75 Cordero ML, Sandi C: A role for brain glucocorticoid receptors in contextual fear conditioning: dependence upon training intensity. Brain Res 1998;1-2:11-7.

76 Pavlides C, McEwen BS: Effects of mineralocorticoid and glucocorticoid receptors on long-term potentiation in the CA3 hippocampal field. Brain Res 1999;51:204-214.

77 Pavlides C, Ogawa S, Kimura A, McEwen BS: Role of adrenal steroid mineralocorticoid and glucocorticoid receptors in long-term potentiation in the CA1 field of hippocampal slices. Brain Res 1996;38:229-235.

78 Montaron MF, Piazza PV, Aurousseau C, Urani A, Le Moal M, Abrous DN: Implication of corticosteroid receptors in the regulation of hippocampal structural plasticity. Eur J Neurosci 2003;18:3105-3111.

79 Khaksari M, Rashidy-Pour A, Vafaei AA: Central mineralocorticoid receptors are indispensable for corticosterone-induced impairment of memory retrieval in rats. Neuroscience 2007;149:729-738.

-80 Zhou M, Bakker EH, Velzing EH, Berger S, Oitzl M, Joëls M, Krugers HJ: Both mineralocorticoid and glucocorticoid receptors regulate emotional memory in mice. Neurobiol Learn Mem 2010;94:530-537.

-81 Christensen H, Boysen G, Johannesen HH: Serum-cortisol reflects severity and mortality in acute stroke. J Neurol Sci 2004;217: 175-180. 